\title{
The Nonplanar Peptide Unit.*,+ III. Quantum Chemical Calculations for Related Compounds and Experimental X-Ray Diffraction Data
}

\author{
A. S. KOLASKAR, Molecular Biophysics Unit, Indian Institute of \\ Science, Bangalore 560012, India; A. V. LAKSHMINARAYANAN $\dagger \dagger$ \\ and K. P. SARATHY, Department of Biophysics and Theoretical \\ Biology, University of Chicago, Chicago, Illinois 60637; and \\ V. SASISEKHARAN, $\dagger$ Molecular Biophysics Unit, Indian Institute \\ of Science, Bangalore 560012, India and Department of Biophysics \\ and Theoretical Biology, University of Chicago, Chicago, Illinois 60687
}

\begin{abstract}
Synopsis
The possible nonplanar distortions of the amide group in formamide, acetamide, $N$-methylacetamide, and $N$-ethylacetamide have been examined using $\mathrm{CNDO} / 2$ and INDO methods. The predictions from these methods are compared with the results obtained from X-ray and neutron diffraction studies on crystals of small open peptides, cyclic peptides, and amides. It is shown that the INDO results are in good agreement with observation, and that the dihedral angles $\theta_{\mathrm{N}}$ and $\Delta \omega$ defining the nonplanarity of the amide unit are correlated approximately by the relation $\theta_{\mathrm{N}}=-2 \Delta \omega$, while $\theta_{\mathrm{C}}$ is small and uncorrelated with $\Delta \omega$. The present study indicates that the nonplanar distortions at the nitrogen atom of the peptide unit may have to be taken into consideration, in addition to the variation in the dihedral angles $(\phi, \psi)$, in working out polypeptide and protein structures.
\end{abstract}

\section{INTRODUCTION}

In Part $\mathrm{I}^{1}$ it was shown using the $\mathrm{CNDO} / 2$ method that the minimum energy conformation for $N$-methylacetamide is one in which the three bonds meeting at the nitrogen atom have a pyramidal configuration, rather than a planar one. The distortions were characterized by the nonzero values of the dihedral angles $\theta_{\mathrm{N}}$ and $\Delta \omega$ (see Part I for definition). The calculations in Ref. 1 were made by using standard data for bond lengths and bond angles, as given in the review by Ramachandran and

\footnotetext{
* Contribution No. 58 from the Molecular Biophysics Unit, Indian Institute of Science, Bangalore, India.

+ Parts I and II of this series have appeared in Biochim. Biophys. Acta, Vol. 303 (1973).

$\dagger$ To whom reprint requests are to be sent.

$\dagger \dagger$ Present address: Department of Computer Science, State University of New York at Buffalo, 26 Ridgelea Road, Amherst, New York 14226.
} 
Sasisekharan. ${ }^{2}$ Some of the observed data of crystal structures of simple peptides were analyzed in Part $\mathrm{II},{ }^{3}$ and it was shown that appreciable deviations from strict planarity could occur and also that the observed data lay close to the line $\theta_{N}=-2 \Delta \omega$ in the graph drawn with those two parameters as the coordinates. On the other hand, there was no correlation between the dihedral angles $\Delta \omega$ and $\theta_{\mathrm{C}}$. In view of the great importance of the exact nature of the nonplanarity of the peptide unit to the studies on proteins and polypeptides, we have now applied the CNDO/2 method to other related molecules-namely formamide, acetamide, and $N$-ethylacetamide - and the results are presented in this paper. We have, in addition, applied the INDO method (proposed by Pople et al. ${ }^{4}$ ) to the case of formamide, acetamide, and $N$-methylacetamide.

We have also extended our analysis of the observed data of crystal structures (from peptides and their derivatives) to those of amides and of peptides containing residues such as proline, in which a hydrogen atom is not attached to the nitrogen. The Fortran IV computer program, QCPE 141, obtained from the Quantum Chemistry Program Exchange, Indiana University, Bloomington, Indiana, was used for all calculations.

\section{RESULTS OF QUANTUM CHEMICAL CALCULATIONS}

\section{Formamide}

The geometry used for the formamide molecule is the average geometry of the peptide unit found in small oligopeptides and as used in our previous study made on the molecule of $N$-methylacetamide ${ }^{1}$ (i.e., $\mathrm{C}-\mathrm{N}=1.32 \AA$ and $\mathrm{C}=\mathrm{O}=1.24 \AA$ ). Standard values of $1.1 \AA$ and $1.0 \AA$ have been uniformly adopted for $\mathrm{C}-\mathrm{H}$ and $\mathrm{N}-\mathrm{H}$ bond lengths and a uniformly averaged value of $120^{\circ}$ for the bond angles.

The energy of the molecule was calculated employing both the CNDO/2 and the INDO approximations. A range of values at intervals of $5^{\circ}$, from 0 to $35^{\circ}$, for $\Delta \omega$, and -40 to $20^{\circ}$ for $\theta_{N}$, was employed. The variation of energy calculated using the CNDO/2 method for formamide with $\Delta \omega$ and $\theta_{\mathrm{N}}$ is shown in Figure 1a, in terms of isoenergy contours at intervals of 0.5 $\mathrm{kcal} / \mathrm{mole}$. The total energy for a planar conformation was taken to be $0.0 \mathrm{kcal} / \mathrm{mole}$. The minimum energy conformation (marked in the figure) occurs at $\Delta \omega=20^{\circ}$ and $\theta_{N}=-35^{\circ}$. This energy is lower than that for the planar conformation by $1.32 \mathrm{kcal} / \mathrm{mole}$.

The results obtained from INDO calculations are shown in Figure 1b. These calculations show that, for the same input geometry, the planar conformation (marked $X$ in the figure) of the formamide molecule has the minimum energy. However, the extent of the region enclosed by the first isoenergy contour at $+0.5 \mathrm{kcal} / \mathrm{mole}$ clearly shows that conformations, with deviations as large as $\Delta \omega=10^{\circ}$ and $\theta_{\mathrm{N}}=-25^{\circ}$, are quite probable. It is of interest that both INDO and CNDO/2 calculations show that, for the values of $\Delta \omega \neq 0^{\circ}$ the minimum occurs for $\theta_{N} \neq 0^{\circ}$. Thus, for $\Delta \omega=$ $10^{\circ}, \mathrm{CNDO} / 2$ calculations give the energy minimum at $\theta_{\mathrm{N}} \approx-25^{\circ}$, while INDO calculations give it at about $-20^{\circ}$. 


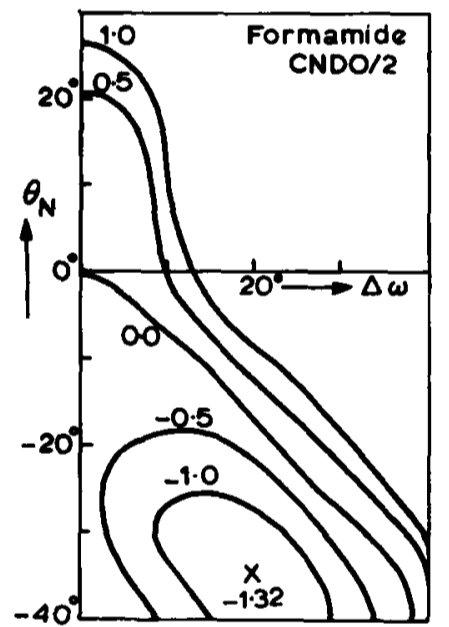

(a)

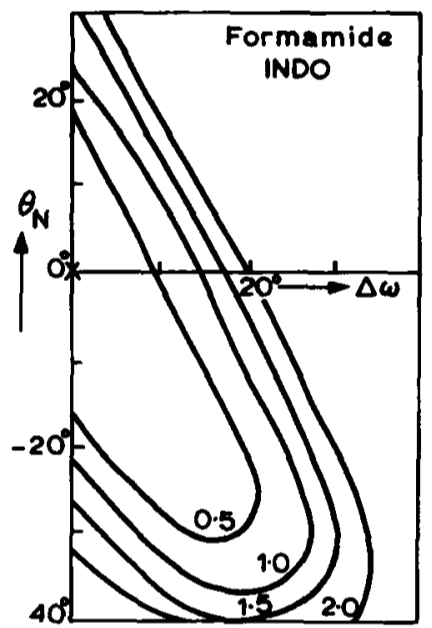

(b)

Fig. 1. Isoenergy contours in the plane $\left(\Delta \omega, \theta_{\mathrm{N}}\right)$ at intervals of $0.5 \mathrm{kcal} / \mathrm{mole}$ for the formamide molecule. The energy was taken to be $0.0 \mathrm{kcal} / \mathrm{mole}$ for the planar conformation (a) using the CNDO/2 method, (b) using the INDO method.

\section{Acetamide}

In order to study the effect of the methyl group attached to the $\mathrm{C}_{1}{ }^{\alpha}$ carbon atom on nonplanar distortions, we have carried out, as a first step, computations for the acetamide molecule without modifying the initial geometry of the formamide, or peptide, skeleton. The methyl group was assumed to have regular tetrahedral angles of $109.5^{\circ}$, with the $\mathrm{C}-\mathrm{H}$ bond length equal to $1.1 \AA$. The single bond $\mathrm{C}-\mathrm{C}$ was assumed to be $1.53 \AA$. The variation of total energy with $\Delta \omega$ and $\theta_{N}$ is shown in Figures $2 a$ and $2 \mathrm{~b}$, respectively, by isoenergy contours, for the CNDO/2 and the INDO

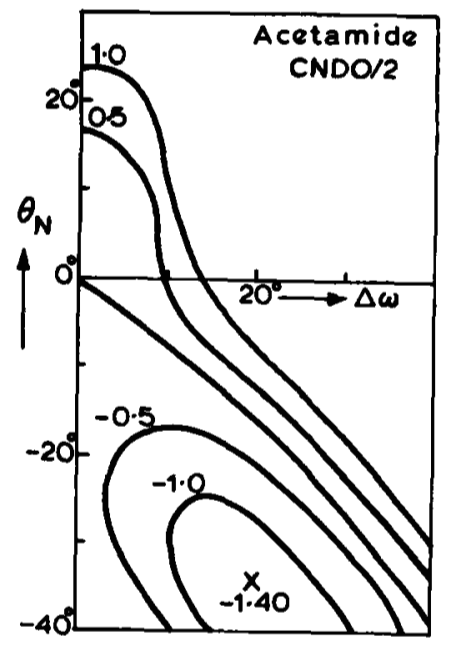

(a)

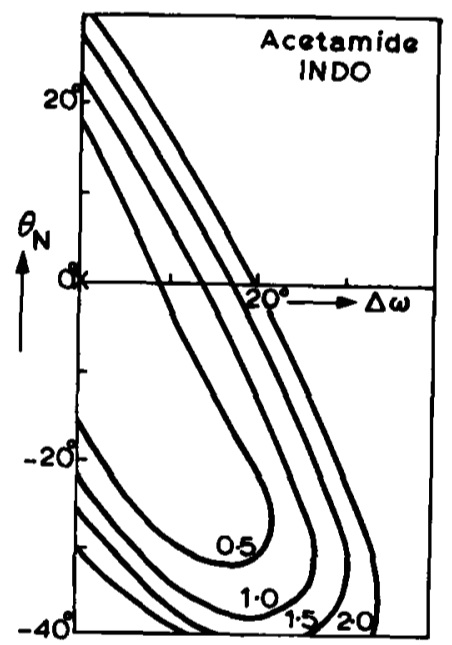

(b)

Fig. 2. Similar to Fig. 1, but with the coutours drawn for the acetamide molecule. 


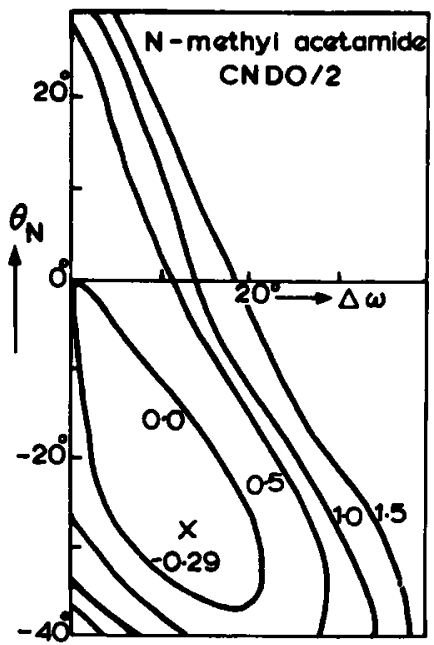

(a)

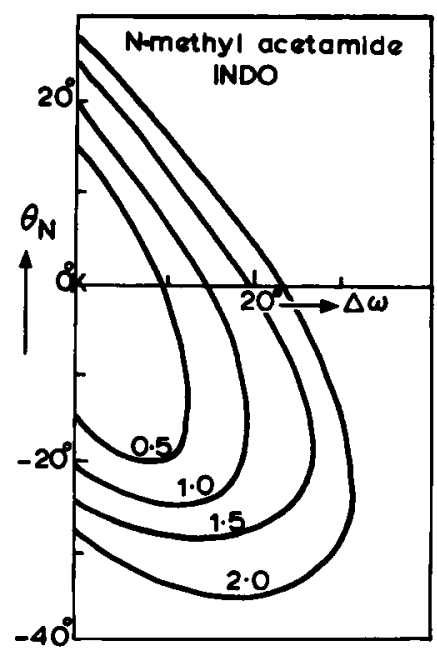

(b)

Fig. 3. Similar to Fig. 1, but with contours representing the variation of energy for $N$-methylacetamide.

calculations, respectively. The trends shown are similar to formamide. The CNDO/ 2 calculations show that a nonplanar conformation with $\Delta \omega$ in the range $10-30^{\circ}$ leads to decreasing energy values for nonzero values of $\theta_{\mathrm{N}}$ up to $-40^{\circ}$, when compared to the planar conformation, and that the minimum of about $-1.4 \mathrm{kcal} /$ mole with reference to the energy for $\left(0^{\circ}, 0^{\circ}\right)$ occurs at $\Delta \omega=20^{\circ}$ and $\theta_{N}=-35^{\circ}$ (see Fig. 2a). The INDO energy for any nonplanar conformation is larger than that for the planar conformation. However, nonplanar distortions of the order of $\Delta \omega \approx 15^{\circ}, \theta_{\mathrm{N}} \approx-25^{\circ}$, are very likely to cocur, since the energy change for this deviation from planarity is only of the order of $0.5 \mathrm{kcal} / \mathrm{mole}$.

\section{$\boldsymbol{N}$-Methylacetamide}

The input geometry used for the $N$-methylacetamide molecule was the same as the one mentioned in Ref. 1 with methyl hydrogens in staggered positions about the $\mathrm{C}^{\alpha}-\mathrm{C}$ and the $\mathrm{N}-\mathrm{C}^{\alpha}$ bonds. (The results of our calculations made using CNDO/2 and INDO methods with different orientations for methyl groups, such as the eclipsed or the staggered, about the $\mathrm{C}^{\alpha}-\mathrm{C}$ or the $\mathrm{N}=\mathrm{C}^{\alpha}$ bond show that there is very little effect on the minimum energy conformation obtained with respect to nonplanar distortions. Therefore, these results are not presented here.) The energy variation for $N$-methyl acetamide using $\mathrm{CNDO} / 2$ and INDO approximations are shown in Figures $3 a$ and $3 b$. The results are similar to those for either acetamide or formamide, and the variation in energy also follows the same trend.

\section{$N$-Ethylacetamide}

This is a good model compound for the glycyl dipeptide. The geometry used for this molecule was the same as that for $N$-methylacetamide. The 
ethyl group was fixed in the usual manner by taking $\mathrm{C}-\mathrm{C}$ and $\mathrm{C}-\mathrm{H}$ bond lengths equal to $1.53 \AA$ and $1.1 \AA$, respectively. The bond angles were assumed to be tetrahedral, of value $109.5^{\circ}$. For $\phi$ in the range -180 to $0^{\circ}$, the energy of the $N$-ethylacetamide molecule was calculated using the $\mathrm{CNDO} / 2$ method at $30^{\circ}$ intervals, assuming the peptide skeleton to be planar. ( $\phi$ is defined, following IUPAC-IUB conventions. ${ }^{7}$ ) The energy was found to be minimum for $\phi=-180^{\circ}$. Therefore the ethyl group was fixed in this conformation and computations were carried out by varying $\Delta \omega$ and $\theta_{\mathrm{N}}$ in the range -30 to $+30^{\circ}$. The energy minimum occurred at $\Delta \omega= \pm 10^{\circ}$ and $\theta_{\mathrm{N}}= \pm 20^{\circ}$. The energy difference between the conformation $\left(10^{\circ},-20^{\circ}\right)$ and the planar conformation $\left(0^{\circ}, 0^{\circ}\right)$ was found to be only $0.16 \mathrm{kcal} / \mathrm{mole}$.

In order to see the effect of $\phi$ on nonplanar distortions, calculations were repeated by fixing the ethyl group in the conformation $\phi=-120^{\circ}$. For this conformation of the ethyl group also, the energy minimum occurred at $\left(10^{\circ},-20^{\circ}\right)$. The energy difference between the conformation $\left(10^{\circ},-20^{\circ}\right)$ and the planar conformation (with $\phi=-120^{\circ}$ ) was found to be 0.20 $\mathrm{kcal} / \mathrm{mole}$. We also found that the conformation at $\phi=-180^{\circ}$ is more stable than that for $\phi=-120^{\circ}$ by about $+0.20 \mathrm{kcal} / \mathrm{mole}$, both for the planar as well as for the conformation $\left(10^{\circ},-20^{\circ}\right)$. The variation of total energy with $\Delta \omega$ and $\theta_{\mathrm{N}}$ for $N$-ethylacetamide for $\phi=-120^{\circ}$ is shown in Figure 4a. The isoenergy contours at $0.5 \mathrm{kcal} / \mathrm{mole}$ intervals, as drawn in Figure 4a, indicate that they are nearly symmetric, though they will not be exactly symmetric in the case of $N$-ethylacetamide except for $\phi=-180$ and $0^{\circ}$. Thus, these calculations indicate that there is practically no effect of $\phi$ on nonplanar distortions, at least for $N$-ethylacetamide.

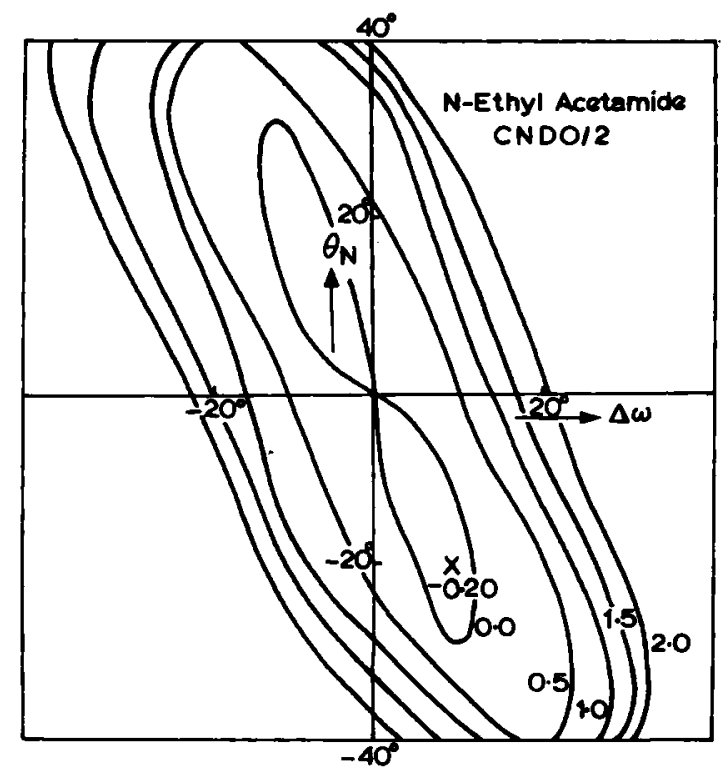

(a)

Fig. 4 (continued) 


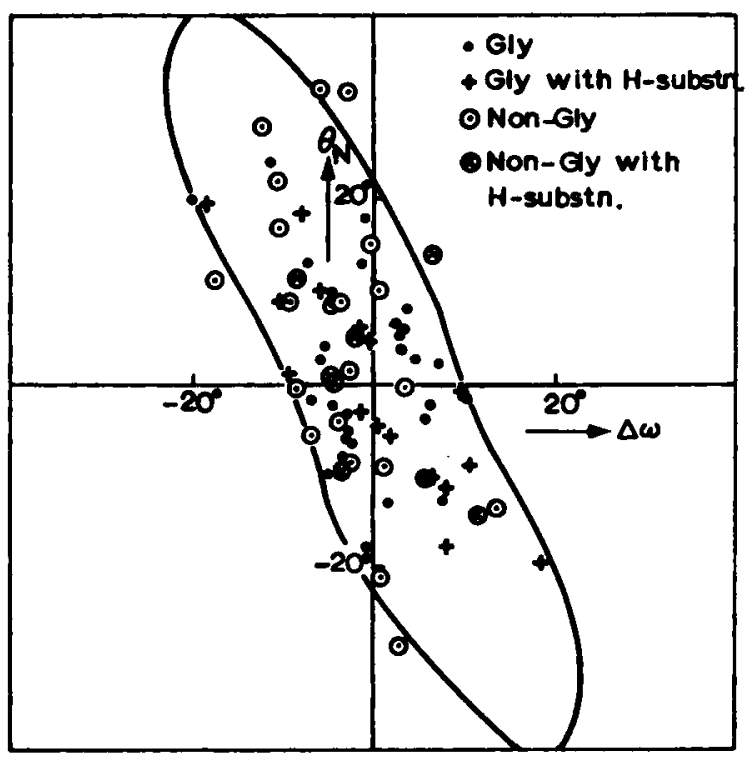

(b)

Fig. 4. (a) Isoenergy contours drawn for $N$-ethylacetamide at intervals of $0.5 \mathrm{kcal} /$ mole. Minima are marked by the symbol $X$. (b) Observed conformation $\left(\Delta \omega, \theta_{N}\right)$ from $X$-ray and neutron diffraction data. The values of $\left(\Delta \omega, \theta_{N}\right)$ as given in Table $I$ are plotted with $\Delta \omega$ and $\theta \mathrm{N}$ and $x$ and $y$ coordinates: (๑) represents glycyl residues; $(\odot)$ represents nonglycyl residues; $(X)(\otimes)$, represent, respectively, glycyl and nonglycyl residues in which the hydrogen atom attached to the nitrogen in the peptide skeleton is replaced by a carbon atom (as for example, in the case of the proline residue). Note that most of the points lie in the low-energy region of the map (the $0.5 \mathrm{kcal} / \mathrm{mole}$ contour is shown) and follow roughly the correlated variation given by $\theta_{\mathrm{N}}=-2 \Delta \omega$.

\section{ANALYSIS OF OBSERVED CRYSTAL STRUCTURE DATA}

During the last three or four years, hydrogen atoms have been fairly accurately located in crystals using $\mathrm{X}$-ray and neutron diffraction techniques, and consequently, one could estimate values of $\left(\theta_{N}, \Delta \omega\right)$ from crystal structures fairly reasonably. In Part $\mathrm{II}^{2}$ we reported the values of $\theta_{\mathrm{N}}$, $\Delta \omega$, and $\theta_{\mathrm{C}}$ as obtained from the data of crystal structures of simple peptides. Since our theoretical calculations on simple amides such as formamide, acetamide, $N$-methylacetamide, and $N$-ethylacetamide show that nonplanar distortions are likely to occur in all these cases, we have now calculated the values of $\theta_{N}, \theta_{\mathrm{C}}$, and $\Delta \omega$ from the available crystal structure data of various such compounds for which hydrogen atom positions have been located. The compounds may be broadly divided into three categories, namely, (a) open peptides, (b) cyclic peptides, and (c) amides other than (a) and (b). The values of the three parameters which define the nonplanarity of the peptide unit are given in Table $I$. The values given in Table I are only for peptides in the trans configuration. Though nonplanar distortions have been observed in cyclic peptides having cis peptide 
bonds, we have not included the data of such compounds in this paper because our theoretical calculations reported here are for trans-amides. Theoretical calculations made on $N$-methylacetamide with cis configuration for the amide and the comparison of these results with observed data on cyclic peptides in cis configuration will be reported in a separate communication.

The conformations $\left(\Delta \omega, \theta_{\mathrm{N}}\right)$ for the compounds as given in Table $I$ are also plotted in Figure $4 \mathrm{~b}$, in which the $0.5 \mathrm{kcal} /$ mole contour of Figure $4 \mathrm{a}$

TABLE I

Values of Dihedral Angles $\Delta \omega, \theta_{\mathrm{N}}$, and $\theta_{\mathrm{C}}$ from X-Ray and Neutron Diffraction Data for Open Peptides, Cyclic Peptides, and Amides

\begin{tabular}{|c|c|c|c|c|}
\hline Compound & $\begin{array}{c}\Delta \omega, \\
\text { degrees }\end{array}$ & $\begin{array}{c}\theta_{\mathrm{N}}, \\
\text { degrees }\end{array}$ & $\begin{array}{c}\theta_{\mathrm{C}}, \\
\text { degrees }\end{array}$ & $\begin{array}{c}\text { Technique } \\
\text { and ref. } \\
\text { no. }\end{array}$ \\
\hline \multicolumn{5}{|c|}{ Open peptides } \\
\hline Gly-L-Leu & -11.4 & +24.1 & +0.2 & $\mathrm{X}, 8$ \\
\hline Gly-Gly, $\mathrm{HCl}, \mathrm{H}_{2} \mathrm{O}$ & -3.2 & -3.5 & -2.4 & $\mathrm{~N}, 9$ \\
\hline$\alpha-G l y-G l y$ & +3.6 & +8.2 & +3.3 & $\mathbf{N}, 10$ \\
\hline L-Ala-Gly & -6.1 & +2.5 & -2.0 & $\mathrm{X}, 11$ \\
\hline L-Ala-L-Ala & -4.3 & -3.9 & -1.6 & $\mathrm{X}, 12$ \\
\hline \multirow[t]{2}{*}{ Glutathione } & +13.7 & -13.4 & +3.7 & $\mathrm{X}, 13$ \\
\hline & +2.6 & +6.4 & +1.2 & \\
\hline DL- $N$-Chloroacetyl-Ala & -4.9 & +8.7 & -0.5 & $X, 14$ \\
\hline Gly-Gly phosphate monohydrate & -4.5 & -9.7 & +0.2 & $X, 15$ \\
\hline$N$-Methyldipropyl acetamide & -0.1 & +15.3 & -0.8 & $X, 16$ \\
\hline Gly-L-Ala, $\mathrm{HCl}$ & -10.7 & +17.2 & +4.5 & $X, 17$ \\
\hline Me-DL-Leu-Gly, $\mathrm{HBr}$ & -1.1 & -17.9 & +2.2 & $\mathrm{X}, 18$ \\
\hline L-Ala-L-Ala, $\mathrm{HCl}$ & +0.8 & -21.1 & -2.7 & $\mathrm{X}, 19$ \\
\hline L-Ala-Gly, $\mathrm{HBr}$ & +7.2 & +2.0 & -2.5 & $\mathrm{X}, 20$ \\
\hline Gly-Gly nitrate & -5.5 & +4.3 & -1.0 & $\mathrm{X}, 21$ \\
\hline \multirow[t]{2}{*}{ Ac-L-Phe-L-Tyr } & +3.5 & -0.1 & +0.3 & $X, 22$ \\
\hline & -17.7 & +11.4 & +6.2 & \\
\hline \multirow[t]{2}{*}{ Ac-L-Pro-I-methyl acetamide } & -2.7 & -8.6 & +1.2 & $\mathrm{X}, 23$ \\
\hline & $-8.4^{\mathrm{b}}$ & -11.4 & +1.3 & \\
\hline \multirow[t]{2}{*}{ L-Leu-L-Pro-Gly } & $-4.8^{b}$ & +1.0 & -4.2 & $\mathrm{X}, 24$ \\
\hline & -4.4 & -2.6 & -4.0 & \\
\hline \multirow[t]{3}{*}{$\beta$-Br- $\mathrm{Cb}_{3}-\mathrm{Gly}$-Pro-Leu-Gly } & $+5.6^{\mathrm{b}}$ & -9.6 & -3.1 & $\mathrm{X}, 25$ \\
\hline & +0.7 & -9.1 & +0.6 & \\
\hline & +2.7 & +5.2 & +2.1 & \\
\hline Tos-L-Pro-L-Hypro monohydrate & $-4.5^{\mathrm{b}}$ & +0.2 & -0.8 & $X, 26$ \\
\hline $\mathrm{O}-\mathrm{Br}-\mathrm{Cb}_{2}$-Gly-L-Pro-L-Leu-L & $+11.5^{b}$ & -14.5 & -2.0 & $\mathrm{X}, 27$ \\
\hline \multirow[t]{3}{*}{ Gly-I-Pro-EtAc } & +2.3 & +4.8 & +2.6 & \\
\hline & +2.1 & N.L. & -3.7 & \\
\hline & $-2.2^{\mathrm{b}}$ & +5.1 & +0.9 & \\
\hline \multicolumn{5}{|l|}{$N$-Methyl-2,4,6-trinitroacet- } \\
\hline anilide & $+5.8^{b}$ & -10.2 & +0.0 & $\mathrm{X}, 28$ \\
\hline \multicolumn{5}{|l|}{ 4-Diethyl carbamoyl-1-cyclo- } \\
\hline hexane-5-carboxylic acid & $+6.5^{\mathrm{b}}$ & +14.0 & +4.5 & $\mathrm{X}, 29$ \\
\hline 5 -Br-12S tetrahydroaustamide & $-3.6^{b}$ & -9.4 & -2.1 & $\mathrm{X}, 30$ \\
\hline
\end{tabular}


TABLE I (continued)

\begin{tabular}{|c|c|c|c|c|}
\hline Compound & $\begin{array}{c}\Delta \omega \\
\text { degrees }\end{array}$ & $\begin{array}{c}\theta_{\mathrm{N}}, \\
\text { degrees }\end{array}$ & $\begin{array}{c}\theta_{\mathrm{C}}, \\
\text { degrees }\end{array}$ & $\begin{array}{c}\text { Technique } \\
\text { and ref. } \\
\text { no. }\end{array}$ \\
\hline \multicolumn{5}{|c|}{ Cyclic peptides } \\
\hline -Gly-Gly-D-Ala-D-Ala-Gly-Gly & $\begin{array}{l}+1.4 \\
+2.8 \\
-3.7 \\
+8.2 \\
+3.0 \\
-7.4\end{array}$ & $\begin{array}{c}-13.1 \\
-28.5 \\
+9.2 \\
\text { N.L. } \\
+5.8 \\
+13.1\end{array}$ & $\begin{array}{l}-0.9 \\
+1.1 \\
-1.5 \\
+4.2 \\
-0.7 \\
+1.0\end{array}$ & $\mathrm{X}, 31$ \\
\hline Cyclotetrasarcosyl & $+9.4^{b}$ & -1.3 & +3.2 & $\mathrm{x}, 32$ \\
\hline Cyclooctasarcosyl & $\begin{array}{l}-10.4^{b} \\
-1.8^{b} \\
-8.2^{b} \\
-6.1^{b}\end{array}$ & $\begin{array}{r}+8.9 \\
+5.7 \\
+18.3 \\
+10.1\end{array}$ & $\begin{array}{l}-3.1 \\
-0.6 \\
-0.5 \\
+0.4\end{array}$ & $\mathrm{x}, 33$ \\
\hline Cyclopentasarcosyl & $\begin{array}{r}-0.1^{\mathrm{b}} \\
-18.5^{\mathrm{b}}\end{array}$ & $\begin{array}{r}+4.6 \\
+19.5\end{array}$ & $\begin{array}{l}+0.5 \\
-2.0\end{array}$ & $X, 34$ \\
\hline Li-antamanide & $\begin{array}{l}-1.5^{\mathrm{b}} \\
+8.1^{\mathrm{b}}\end{array}$ & $\begin{array}{r}-3.1 \\
-11.4\end{array}$ & $\begin{array}{l}+2.2 \\
+4.9\end{array}$ & $\mathrm{X}, 35$ \\
\hline \multicolumn{5}{|c|}{ Amides } \\
\hline $\begin{array}{l}\text { 2-( } N \text {-Nitrosomethylamino- } \\
\text { acetamide) }\end{array}$ & $\begin{array}{l}-7.0 \\
-9.4\end{array}$ & $\begin{array}{l}-5.5 \\
+9.2\end{array}$ & $\begin{array}{l}-0.6 \\
-1.2\end{array}$ & $\mathrm{X}, 36$ \\
\hline Difluoroacetamide & -8.4 & -0.6 & -3.8 & $\mathrm{X}, 37$ \\
\hline Picolinamide & +0.5 & +10.3 & +0.2 & $\mathrm{X}, 38$ \\
\hline$N$-Methyl benzamide & -5.8 & +31.9 & -2.3 & $\mathrm{X}, 39$ \\
\hline$N$-Hydroxy benzamide & -12.5 & +28.0 & +1.3 & $\mathrm{X}, 40$ \\
\hline L-Asparagine monohydrate & -2.7 & +1.6 & +0.5 & $\mathrm{~N}, 41$ \\
\hline Hippuric acid & -2.9 & +31.7 & +0.1 & $\mathrm{X}, 42$ \\
\hline
\end{tabular}

$\mathrm{X}=\mathrm{X}$-ray, $\mathrm{N}=$ neutron diffraction.

b Denotes that the $\mathrm{H}$ in the $\mathrm{N}-\mathrm{H}$ of the peptide skeleton is replaced by a $\mathrm{C}$ (as in the case of a proline residue).

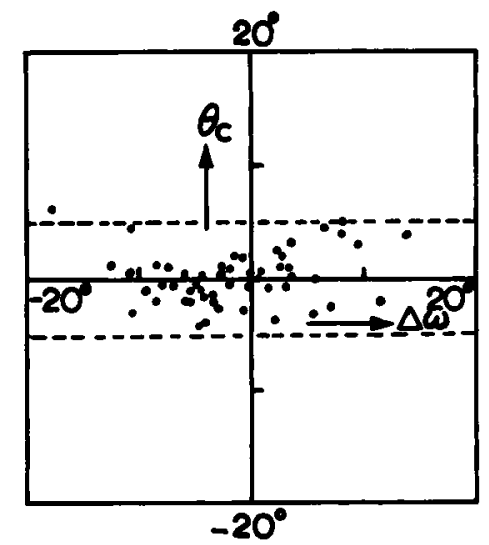

Fig. 5. Distribution of observed data, given in Table $I$, in the $\left(\Delta \omega, \theta_{\mathrm{C}}\right)$ plane. Note that $\theta \mathrm{C}$ is rarely larger than $5^{\circ}$ and there is no correlated variation between $\Delta \omega$ and $\theta_{\mathrm{C}}$. 
is also marked. The glycyl residues are shown by dots (•) and the nonglycyl residues by circles $(\odot)$. In molecules like proline peptides in which the hydrogen atoms attached to the amide nitrogen is replaced by a carbon atom (i.e., exists as imido $N$ ), glycyl residues are marked as $(X)$ and nonglycyl residues as $(\otimes)$. In Table $I$, these residues are marked by an asterisk. The variation of $\Delta \omega$ and $\theta_{\mathrm{C}}$ is likewise shown in Figure 5 .

It can be seen from these figures that $\Delta \omega$ and $\theta_{\mathrm{N}}$ are correlated and almost all the observed conformations lic inside the $0.5 \mathrm{kcal} / \mathrm{mole}$ energy contour, as obtained for $N$-ethylacetamide, using the $\mathrm{CNDO} / 2$ method. The values of $\theta_{\mathrm{C}}$ are rarely larger than $5^{\circ}$ and lie uniformly on either side of the $\Delta \omega$ axis.

\section{DISCUSSION}

\section{Formamide}

The location $\left(20^{\circ},-35^{\circ}\right)$ for the minimum energy conformation of the formamide molecule (as obtained from $\mathrm{CNDO} / 2$ calculations) is much further removed from planarity $\left(0^{\circ}, 0^{\circ}\right)$ than the observed conformation $\left(7^{\circ},-19^{\circ}\right)$ as obtained in the microwave study of Costain and Dowling. ${ }^{5}$ On the other hand, INDO calculations indicate that, for a fixed input geometry of the formamide molecule, the energy is lowest for $\left(0^{\circ}, 0^{\circ}\right)$, but that a very broad valley extending up to $\left(10^{\circ},-25^{\circ}\right)$ even for the contour with $0.5 \mathrm{kcal} / \mathrm{mole}$, in the direction $\theta_{\mathrm{N}}=-2 \Delta \omega$, exists. In fact, recent microwave studies of Hirota et al.$^{6}$ made with the formamide molecule indicate a situation not too different from the predictions of our INDO calculations. Hirota et al. ${ }^{6}$ assumed that the nomplanar deviations occur in a symmetrical way as indicated in Figure 6, i.e., the magnitudes of angles $\Delta \omega$ and $\Delta v$ are equal (here $\omega$ is the dihedral angle $\mathrm{H}_{3}-\mathrm{C}-\mathrm{N}-\mathrm{H}_{1}$ and $v$ is $\mathrm{H}_{3}-\mathrm{C}-\mathrm{N}-\mathrm{H}_{2}$, which means that $\left.\Delta v=+\Delta \omega\right)$. This type of variation as used by them, namely, $\Delta \omega=-\Delta v$, corresponds to the equation $\theta_{\mathrm{N}}=-2 \Delta \omega$, which is the probable type of deformation predicted by our theory for all molecules discussed here. The effect of variation of geometry, in particular the variation of bond angles at the nitrogen atom of the formamide molecule will be discussed in the next part of this series. In summary, these calculations made using the CNDO/2 method also indicate that the nonplanar conformation is more stable as compared to the planar conformation of the molecule and suggest that the nitrogen atom of the amide group in

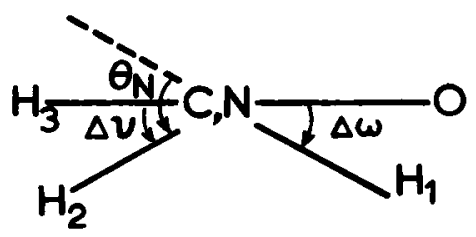

Fig. 6. Diagram showing the definition of the dihedral angles $\Delta \omega$ and $\theta_{\mathrm{C}}$ and $\Delta v$. 
formamide has a large pyramidal character. However, the INDO calculations again yield a shallow minimum corresponding to the planar conformation, indicating that nonplanar distortions can occur readily.

\section{Acetamide, $\boldsymbol{N}$-Methylacetamide, and $\boldsymbol{N}$-Ethylacetamide}

Both the CNDO/2 and INDO calculations show similar trends for formamide and acetamide. Thus, it is seen that a methyl group attached to the carbonyl carbon atom has very little effect on the possible nonplanar distortions of the peptide skeleton. However, a comparison of $N$-methylacetamide with acetamide indicates that a methyl group attached to the nitrogen leads to a decrease in the pyramidal character of the nitrogen atom. On the other hand, on increasing further the bulk of the group attached to $\mathrm{N}$, as in the case of $N$-ethylacetamide, the pyramidal character is not further reduced. Using the $\mathrm{CNDO} / 2$ method, the difference obtained between the nonplanar minimum and the planar conformation is +0.25 $\mathrm{kcal} /$ mole for $N$-methylacetamide and $0.20 \mathrm{kcal} /$ mole for $N$-ethylacetamide Also, the minimum occurs at about the same position, $\left(\Delta \omega, \theta_{\mathrm{N}}\right)$ in both the cases.

The observed data shown in Figure $4 \mathrm{~b}$ correspond to various side groups attached to the atom $\mathrm{C}_{2}{ }^{\alpha}$. However, no systematic trend could be noticed between the extent of nonplanarity and the bulk of the side group. In fact, all the data obtained from $X$-ray structure analysis lie close to the line $\theta_{N}=-2 \Delta \omega$, and they go out to about $15^{\circ}$ for $|\Delta \omega|$ and up to $30^{\circ}$ for $\left|\theta_{\mathrm{N}}\right|$. Also, no particular differences could be noticed in the trend of the data, with respect to the sign of $\Delta \omega$, although the data plotted in Figure $4 b$ correspond to amino acid residue having an $\mathrm{L}$ configuration (except, of course, in the case of glycyl residues).

As mentioned earlier, no appreciable variations in the minimum energy conformation with regard to nonplanarity were observed when the orientation of the methyl groups were changed for $N$-methylacetamide, or the value of $\phi$ was altered in the case of $N$-ethylacetamide. Thus, the data reported in Table I correspond to different values of $\phi$ in the allowed region and also to different values of the dihedral angle $\chi^{1}$ (at the $\mathrm{C}^{\beta}$ atom), but no systematic correlation between the value of $\phi$, or of $\chi^{1}$, and that of $\Delta \omega$ could be clearly noticed. This indicates that nonplanar distortions arise because of intra-atomic interactions, although the possibility of occurrence of these distortions because of intermolecular forces in crystals cannot be ruled out.

\section{Comparison of CNDO/2 and INDO Results}

As will be seen from Figures 1, 2, and 3, there is a systematic difference between the theoretical predictions obtained using the CNDO/2 and the INDO approximations. In the former case, the energy minima occur at nonzero values of $\left(\Delta \omega, \theta_{N}\right)$ with $\theta_{N} \approx-2 \Delta \omega$, while in the latter the minimum energy is at the origin in the $\left(\Delta \omega, \theta_{\mathrm{N}}\right)$ plane. 


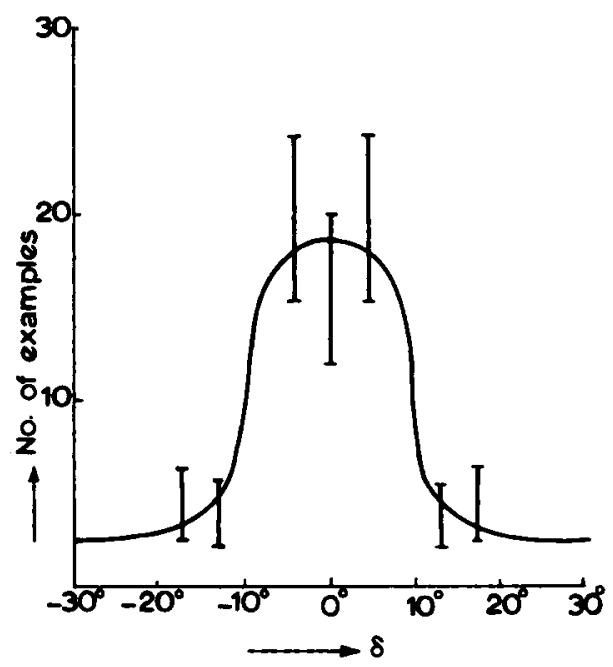

Fig. 7. Statistical distribution in $\left(\Delta \omega, \theta_{N}\right)$ plane as obtained from the data in Table $I$, for symmetrical nonplanar deviations $\delta$, along with their standard deviations. The continuous line indicates a smooth curve drawn through these points.

These differences may be attributed to the properties of the two quantum chemical methods. The CNDO/2 approximation does not make any allowance for spin-spin interactions of electrons, in particular if they are on the same atom, while in the case of the INDO approximation, these interactions are partly taken into account by retaining monoatomic differential overlaps, although only as one-center integrals. However, as accurate structural data are not available for these amides except for formamide, the theoretical predictions cannot be compared or checked directly with the experimental observations. In order to quantitatively compare the two differing theoretical results with the available observed data on peptides, we have used the following procedure: From the observed $\left(\theta_{N}, \Delta \omega\right)$ distribution (as shown in Figure $4 \mathrm{~b}$ ) the probability of these conformations along the line $\theta_{N}=-2 \Delta \omega$ is calculated. This is shown in Figure 7, after normalization along with their standard deviations. This probability distribution, which is approximated to a normal distribution, is then transformed into a variation of energy with $\delta$ (using the Boltzmann distribution law). This expected variation of energy is shown in Figure 8, along with the INDO and CNDO/2 variations of energy along the line $\theta_{\mathrm{N}}=-2 \Delta \omega$ for $N$-methylacetamide. There is a close correspondence between the INDO energy and that deduced from experimental data. However, the curve obtained using the CNDO/2 method is in poor agreement. Thus INDO results fit better with the currently available data. As can be seen from Figure 8 , the $\mathrm{CNDO} / 2$ curve departs significantly near $\delta=0^{\circ}$ from the INDO curve. This may be because of the fact that the CNDO/2 method overemphasizes the orbital overlap term as compared 


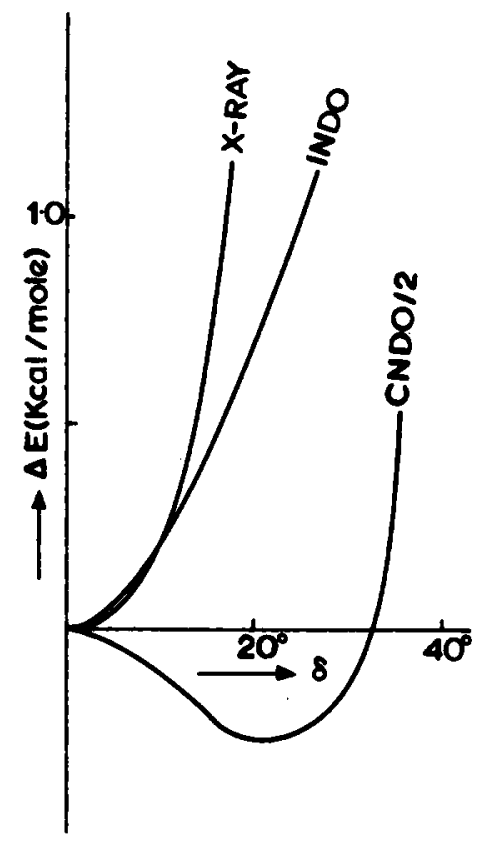

Fig. 8. Variation of $\Delta E$ with $\delta$ in peptide units, using the X-ray data in Fig. 7, as well as curves obtained using INDO and CNDO/2 results for $N$-methylacetamide are shown. (These curves are marked, respectively, as X-ray, INDO, and CNDO/2.) Note the good agreement between the curve obtained using data in Table $I$ and the curve drawn using results of INDO method for $N$-methylacetamide.

to INDO, which might also be the reason for the observed trend of symmetric deformation for which the orbital overlap is maximum.

\section{CONCLÜSIONS}

The results reported in this paper show that nonplanar deformations of the amide unit with $|\Delta \omega|$ up to $15^{\circ}$ and of $\left|\theta_{\mathrm{N}}\right|$ up to $30^{\circ}$ are quite probable, since the energy increase for such deviations from planarity are only of the order of $0.5 \mathrm{kcal} / \mathrm{mole}$. Such a deformation also approximately follows the relation $\theta_{\mathrm{N}}=-2 \Delta \omega$. Our calculations also indicate that tendency towards nonplanarity and for maximum orbital overlap (with respect to rotation about the $\mathrm{C}-\mathrm{N}$ bond) are uncoupled and corresponds roughly to the same amount of energy per degree of deformation (this was pointed out by one of the referees). When such a deformation from rigid planarity of the peptide unit is envisaged, there is no doubt that a polypeptide chain will be enormously more flexible. It is therefore suggested that this added flexibility should be taken into account in model-building techniques in addition to the rotational freedom provided by variation of the dihedral angles $(\phi, \psi)$. The conformational calculations made on a dipeptide unit taking into consideration these deformations and the effect of nonplanarity on regular structures will be reported in a future communication. 
The authors thank Prof. G. N. Ramachandran for the useful discussions with him. The authors are grateful to Prof. E. Hirota for making available the microwave data on formamide prior to publication. The authors wish to thank, in particular, the referees for their very useful suggestions, which have materially improved the contents of the paper. This work was supported by USPHS Grants AM-15964 (in Bangalore) and AM11493 (in Chicago).

\section{References}

1. Ramachandran, G. N., Lakshminarayanan, A. V. \& Kolaskar, A. S. (1973) Biochim. Biophys. Acta 303, 8-13.

2. Ramachandran, G. N. \& Sasisekharan, V. (1968) Advan. Protein Chem. 23, 283438. 387.

3. Ramachandran, G. N. \& Kolaskar, A. S. (1973) Biochim. Biophys. Acta 303, 3852033.

4. Pople, J. A., Beveridge, D. L. \& Dobosh, P. A. (1967) J. Chem. Phys. 47, 2026-

5. Costain, C. C. \& Dowling, J. M. (1960) J. Chem. Phys. 32, 158-165.

6. Hirota, E., Sugisaki, R., Neilsen, C. J. \& Sorensen, G. O. (1974) J. Mol. Struc. 49, 251-267.

7. IUPAC-IUB Commission on Biochemical Nomenclature (1970) Biochem. 9, 3471-3479.

8. Venkatesan, K., personal communication.

9. Koetzle, T. F., Hamilton, C. W. \& Parthasarathy, R. (1972) Acta Crystallog., B28, 2083-2089. 936.

10. Freeman, H. C., Paul, G. L. \& Sabine, T. M. (1970) Acta Crystallog., B26, 925-

11. Koch, H. J. \& Germain, G. (1970) Acta Crystallog. B26, 410-417.

12. Fletterick, R. J., Tsai, C. C. \& Hughes, E. R. (1971) J. Phys. Chem. 75, 918-922.

13. Cole, F. E., personal communication to $K$. Venkatesan.

14. Cole, F. E. (1970) Acta Crystallog. B26, 622-627.

15. Freeman, G. R., Hearn, R. A. \& Bugg, C. E. (1972) Acta Crystallog. B28, 29062916.

16. Grand, A. \& Addad, C. C. (1973) Acta Crystallog. B29, 1149-1159.

17. Naganathan, P. S. \& Venkatesan, K. (1972) Acta Crystallog. B28, 552-556.

18. Chandrasekaran, R. \& Subramanian, E. (1969) Acta Crystallog. B25, 2599-2606.

19. Tokuma, Y., Ashida, T. \& Kakudo, M. (1969) Acta Crystallog. B25, 1367-1373.

20. Declercq, J. P., Meulemans, R., Piret, P. \& Meerssche, M. V. (1971) Acta Crystallog. B27, 539-544.

21. Rao, S. N. \& Parthasarathy, R. (1973) Acta Crystallog. B29, 2379-2388.

22. Stenkamp, R. E. \& Jensen, L. H. (1973) Acta Crystallog. B29, 2872-2878.

23. Matsuzaki, T. \& Iitaka, Y. (1971) Acta Crystallog. B27, , 507-516.

24. Leung, Y. C. \& Marsh, R. E. (19:8) Acta Crystallog. 11, 17-31.

25. Ueki, T., Ashida, T., Kakudo, M., Sasada, Y. \& Kastube, Y. (1969) Acta Crystallog. B25, 1840-1849.

26. Sabesan, M. S. \& Venkatesan, K. (1971) Acta Crystallog. B27, 1879-1883.

27. Ueki, T., Bando, S., Ashida, T. \& Kakudo, M. (1971) Acta Crystallog. B27, 22192231.

28. Christoph, G. G. \& Fleischer, F. B. (1973) Acta Crystallog. B29, 121-130.

29. Pedone, C., Benedetti, E., Immirzi, A. \& Allegra, G. (1970) J. Amer. Chem. Soc. 92, $3549-3552$.

30. Coetzer, J. \& Stein, P. S. (1973) Acta Crystallog. B29, 685-689.

31. Karle, I. L., Gibson, J. W. \& Karle, J. (1970) J. Amer. Chem. Soc. 92, 3755-3760.

32. Groth, P. (1970) Acta Chemica Scand. 24, 780-790.

33. Groth, P. (1973) Acta Chem. Scand. 27, 3217-3226. 
34. Groth, P. (1973) Acta Chemica Scand. 27, 3419-3426.

35. Karle, I. L., personal communication.

36. Templeton, L. K., Templeton, D. H. \& Zalkin, A. (1973) Acta Crystallog. B29, $50-54$.

37. Hughes, D. O. \& Small, R. H. W. (1972) Acta Crystallog. B28, 2520-2524.

38. Takano, T., Sasada, Y. \& Kakudo, M. (1966) Acta Crystallog. 21, 514-522.

39. Orii, S., Nakamura, T., Takaki, Y., Sasada, Y. \& Kakudo, M. (1963) Bull. Chem. Soc. Japan 36, 788-793.

40. Katsube, Y., Sasada, Y. \& Kakudo, M. (1966) Bull. Chem. Soc. Japan 39, 25762583.

41. Verbist, J. J., Lehmann, M. S., Koetzle, T. F. \& Hamilton, W. C. (1972) Acta Crystallog. B28, 3006-3013.

42. Ringertz, H. (1971) Acta Crystallog. B27, 285-291.

Received June 19, 1974

Accepted January 2, 1975 